\title{
Substantial Improvement of Pyridine-Carbene Iridium Water Oxida- tion Catalysts by a Simple Methyl-to-Octyl Substitution
}

\author{
Ilaria Corbucci, ${ }^{\dagger}$ Ana Petronilho, ${ }^{\ddagger}$ Helge Müller-Bunz, ${ }^{\dagger}$ Luca Rocchigiani, ${ }^{\dagger}$ Martin Albrecht, ${ }^{*} \pitchfork$ and Alceo Mac- \\ chioni $^{*, \dagger}$ \\ ${ }^{\dagger}$ Department of Chemistry, Biology and Biotechnology, University of Perugia, Via Elce di Sotto, 8, I-06123, Perugia, Italy ${ }^{\star}$ School of \\ Chemistry and Chemical Biology, University College Dublin, Belfield, Dublin 4, Ireland
}

Supporting Information Placeholder

\begin{abstract}
The substitution of a methyl to an octyl group in the ancillary triazolylidene ligand-an apparently simple variation - induces a more than 10 -fold increase of activity of the corresponding iridium complex in water oxidation catalysis when using cerium(IV) as sacrificial oxidant. Detailed NMR studies suggest that various different molecular species form, all bearing the intact triazolylidene ligand. The octyl substituent is essential for inducing the association of the iridium species thus generating extraordinarily active multimetallic catalytic sites. Their accessibility and steady state concentration is critically dependent on the type of sacrificial oxidant and specifically on the CAN vs catalyst ratio. KEYWORDS: Water Oxidation; Iridium; Homogeneous Catalysis; Mesoionic Carbenes; Aggregation.
\end{abstract}

Water oxidation (WO) to molecular oxygen has been recognized as the essential process for producing reductive equivalents for the storage of solar fuels by means of artificial photosynthesis. ${ }^{1 a-f}$ In addition to its endergonic thermodynamics, WO is complicated kinetically because of the multiproton/multielectron transfers involved, Therefore WO requires a competent catalyst $(\mathrm{C})$ that offers an energetically more feasible reaction pathway. Several WOCs have been reported so $\mathrm{far}^{2 \mathrm{a}-\mathrm{f}, \mathrm{3}}$ including molecular systems which are receiving much attention since their performance can potentially be tailored and optimized by an appropriate selection of the ancillary ligands. ${ }^{4}$ For example, Sun, Llobet and coworkers demonstrated that changing an ancillary ligand in a ruthenium complex from 4-picoline to isoquinoline induces a remarkable 10 -fold increase of activity. ${ }^{5}$

Organometallic iridium-based WOCs constitute a class of compounds that is particularly suitable for exploring ligand tailoring. ${ }^{6}$ Based on Bernhard's pioneering work using $\left[\operatorname{Ir}(\text { ppy })_{2}\left(\mathrm{H}_{2} \mathrm{O}\right)_{2}\right]^{+}($ppy $=2$-phenylpyridine $){ }^{7}$ compounds of formula $\left[\mathrm{Cp}^{*} \operatorname{IrL} L^{1} \mathrm{~L}^{2} \mathrm{~L}^{3}\right] \quad\left(\mathrm{Cp}^{*}=\right.$ pentamethylcyclopentadienyl $\mathrm{C}_{5} \mathrm{Me}_{5}{ }^{-}$) emerged as highly active WOCs. ${ }^{8 a-j}$ The ancillary ligands $L$ in these complexes play a critical role in modulating the catalytic performance and also in determining the nature of the active species, altering e.g. the tendency of the $\mathrm{Cp}^{*}$ ligand to undergo oxidative transformations. ${ }^{9 a-c}$ Such $\mathrm{Cp}^{*}$ oxidation has been suggested to be essential for accessing the true catalytically active species, ${ }^{10 a-b}$ thus emphasizing the relevance of ancillary ligands that bind robustly to iridium in order to maintain a homogeneously operating and molecularly well-defined catalyst, with ${ }^{11 a-b}$ or without $^{12 \mathrm{a}-\mathrm{b}}$ fragments of the modified $\mathrm{Cp}^{*}$ ligand.

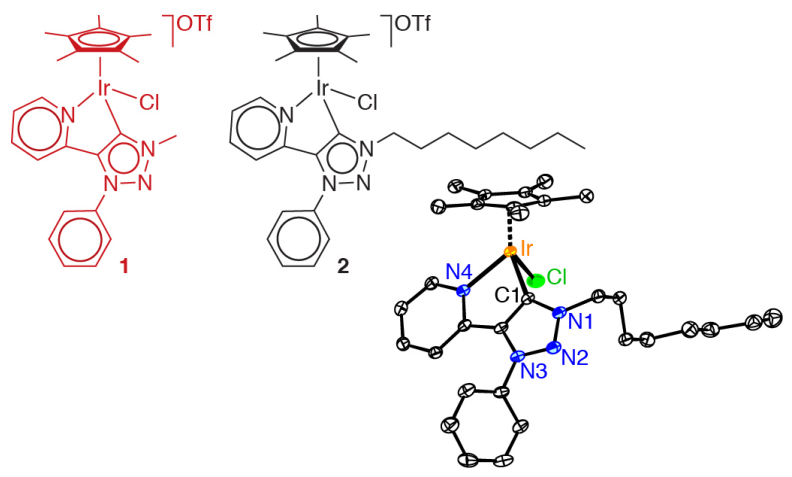

Figure 1. Sketch of iridium WOC precursors 1 and 2 bearing a mesoionic N,C-bidentate carbene ligand, and ORTEP plot (50\% probability ellipsoids) of complex 2 .

We have recently reported highly efficient iridium WOCs containing mesoionic C,C- and N,C-bidentate triazolederived carbene ligands as ancillary ligands. ${ }^{13 a-c}$ Detailed kinetic and mechanistic investigations strongly support a homogeneous mode of action of the most active species, hence warranting further work on ligand tailoring to improve catalytic activity. Herein we report the synthesis of new WOCs based on related mesoionic N,C-bidentate triazolylidene ${ }^{14 a-d}$ ligands (Figure 1) and provide evidence that a peripheral modification of an apparently innocent methyl group to an 
octyl group causes an enormous enhancement of catalytic WO activity when cerium ammonium nitrate (CAN, $\left.\left(\mathrm{NH}_{4}\right)_{2}\left[\mathrm{Ce}\left(\mathrm{NO}_{3}\right)_{6}\right]\right)$ is used as sacrificial oxidant, whereas effects are only marginal with $\mathrm{NaIO}_{4}$ as terminal oxidant. ${ }^{15 \mathrm{a}-\mathrm{b}}$

Complexes $\mathbf{1}$ and $\mathbf{2}$ contain a methyl and an octyl group, respectively, as the triazolylidene $\mathrm{N}$-substituent. These complexes were synthesized in three steps from phenyl azide and 2 -ethynylpyridine. Base-catalyzed [3+2] cycloaddition afforded the 1,5-substituted triazole. ${ }^{16}$ Subsequent alkylation with MeI yielded an easily separable mixture of mono- and dimethylated products while bromooctane addition occurred selectively at the triazole nitrogen. Finally, metalation of the triazolium salts was accomplished via in-situ generation of a silver triazolylidene intermediate followed by transmetalation with $\left[\mathrm{IrCp}^{*} \mathrm{Cl}_{2}\right]_{2}{ }^{13}$

The solid state structure of $\mathbf{2}$ was determined by X-ray diffraction analysis (Figure 1). ${ }^{17}$ Multinuclear and multidimensional NMR experiments allowed the complete assignment of all resonances and revealed high similarity of $\mathbf{1}$ and $\mathbf{2}$. For instance, the carbene carbon nucleus resonates at $157.0 \mathrm{ppm}$

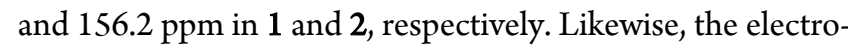
chemical behavior is not significantly altered and no oxidation occurs below $+1.6 \mathrm{~V}$ ( vs NHE).

Complexes 1 and $\mathbf{2}$ were evaluated as WOCs using CAN or $\mathrm{NaIO}_{4}$ as sacrificial oxidant (SO). Catalytic activity was monitored by UV-Vis spectroscopy (consumption of CAN), by manometry, and by Clark electrode measurements $\left(\mathrm{O}_{2}\right.$ evolution). Representative data including TOF and TON values at different concentrations of $\mathrm{SO}$ and iridium complex are summarized in Table $1 .{ }^{17}$ In terms of activity, complex 1 $\left(\mathrm{TOF}_{\max }=16 \mathrm{~min}^{-1}\right.$ and $19 \mathrm{~min}^{-1}$ with CAN and $\mathrm{NaIO}_{4}$, respectively) compares well with the most active iridium WOCs known to date, ${ }^{2 b-c}$ and the rate does not dependent significantly on the catalysts concentration nor on the nature and concentration of the sacrificial oxidant. A similar behavior was noted for the activity of $\mathbf{2}$ with $\mathrm{NaIO}_{4}$ as sacrificial oxidant, although rates $\left(\mathrm{TOF}_{\max }=7 \mathrm{~min}^{-1}\right)$ were slightly lower than for 1. A drastically different behavior was observed for water oxidation with 2 driven by CAN. The activity strongly depends on the concentrations of catalyst and of CAN and reaches much higher rates, $\mathrm{TOF}_{\max }=116 \mathrm{~min}^{-1}$, which are up to one order of magnitude higher than those of 1 and other best-performing iridium-based WOCs (Figure 2).$^{17}$ In order to rationalize the remarkably high and CANdependent activity of complex 2 , a series of comparative catalytic experiments were carried out for $\mathbf{1}$ and $\mathbf{2}$ under identical conditions. These experiments reveal that both complexes 1 and 2 induce identical initial oxygen evolution rates (e.g. $\mathrm{TOF}_{\text {ini }}=10 \mathrm{~min}^{-1}$ in Figure 2). At a specific time, $\mathrm{t}_{\mathrm{B}}=$ bifurcation time, the activity of complex $\mathbf{2}$ increases substantially, while complex 1 continues to produce oxygen at a constant rate identical to $\mathrm{TOF}_{\text {ini }}$ (inset Figure 2).

Table 1. Selected catalytic activity data of WOC precursors 1 and 2. ${ }^{\mathrm{a}}$

\begin{tabular}{|c|c|c|c|c|c|c|c|}
\hline \multirow[t]{2}{*}{ Entry } & \multirow{2}{*}{$\begin{array}{c}\text { [Cat }] \\
/ \mu \mathrm{M}\end{array}$} & \multirow[t]{2}{*}{$\mathrm{SO}$} & \multicolumn{2}{|c|}{ UV-Vis } & \multicolumn{2}{|c|}{ manometry } & \multirow{2}{*}{$\begin{array}{c}\text { Clark } \\
\text { TOF }\end{array}$} \\
\hline & & & TOF & TON & TOF & TON & \\
\hline \multicolumn{8}{|c|}{ WOC 1} \\
\hline 1 & 0.5 & CAN & 10 & 2024 & 16 & 1608 & \\
\hline 2 & 1.0 & CAN & 10 & 1036 & 12 & 1101 & \\
\hline 3 & 2.5 & CAN & 11 & 422 & 12 & 421 & 31 \\
\hline 4 & 5.0 & CAN & 12 & 199 & 13 & 230 & 16 \\
\hline 5 & 1.0 & $\mathrm{CAN}^{\mathrm{c}}$ & 12 & 868 & 10 & 734 & \\
\hline 6 & 2.5 & $\mathrm{CAN}^{\mathrm{c}}$ & 11 & 761 & 11 & 758 & \\
\hline 7 & 5.0 & $\mathrm{CAN}^{\mathrm{c}}$ & 14 & 486 & 9 & 458 & \\
\hline 8 & 1.0 & $\mathrm{NaIO}_{4}$ & & & 19 & 2192 & 14 \\
\hline 9 & 2.5 & $\mathrm{NaIO}_{4}$ & & & 19 & 963 & 9 \\
\hline 10 & 5.0 & $\mathrm{NaIO}_{4}$ & & & 14 & 482 & 7 \\
\hline 11 & 10.0 & $\mathrm{NaIO}_{4}$ & & & 12 & 256 & \\
\hline \multicolumn{8}{|c|}{ WOC 2} \\
\hline 12 & 0.3 & $\mathrm{CAN}^{\mathrm{b}}$ & 53 & 2731 & 61 & 2937 & \\
\hline 13 & 0.5 & $\mathrm{CAN}^{\mathrm{b}}$ & 112 & 1886 & 116 & 2325 & \\
\hline 14 & 1.0 & $\mathrm{CAN}^{\mathrm{b}}$ & 101 & 855 & 95 & 945 & \\
\hline 15 & 2.5 & $\mathrm{CAN}^{\mathrm{b}}$ & 73 & 400 & 66 & 378 & 22 \\
\hline 16 & 5.0 & $\mathrm{CAN}^{\mathrm{b}}$ & 59 & 200 & 48 & 220 & 14 \\
\hline 17 & 1.0 & $\mathrm{CAN}^{\mathrm{c}}$ & 54 & 2356 & 74 & 2430 & \\
\hline 18 & 2.5 & $\mathrm{CAN}^{\mathrm{c}}$ & 69 & 782 & 88 & 990 & \\
\hline 19 & 5.0 & $\mathrm{CAN}^{\mathrm{c}}$ & 59 & 363 & 76 & 463 & \\
\hline 20 & 10.0 & $\mathrm{CAN}^{\mathrm{c}}$ & 34 & 175 & & & \\
\hline 21 & 0.5 & $\mathrm{NaIO}_{4}$ & & & 6 & 1430 & \\
\hline 22 & 1.0 & $\mathrm{NaIO}_{4}$ & & & 7 & 1779 & \\
\hline 23 & 2.5 & $\mathrm{NaIO}_{4}$ & & & 5 & 783 & 1 \\
\hline 24 & 5.0 & $\mathrm{NaIO}_{4}$ & & & 4 & 419 & 2 \\
\hline
\end{tabular}

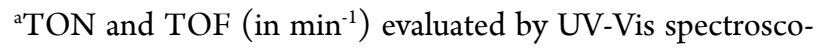
py, manometry and Clark electrode; ${ }^{\mathrm{b}}[\mathrm{SO}]=5 \mathrm{mM}^{\mathrm{c}}[\mathrm{SO}]=$ $10 \mathrm{mM}$.

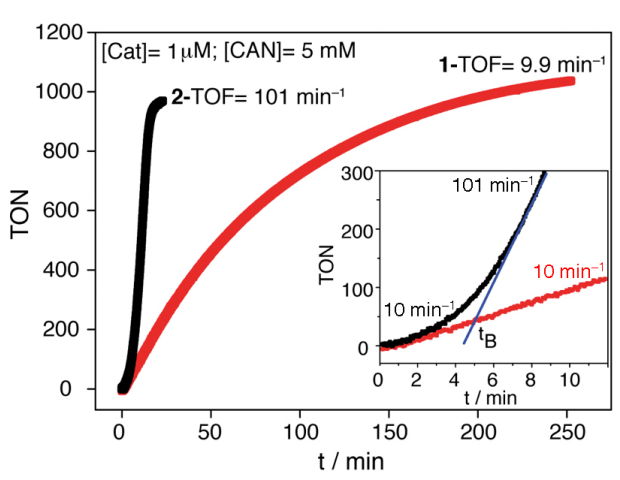

Figure 2. Time-conversion profile for WOCs from 1 and $\mathbf{2}$ measured by UV-Vis spectroscopy (CAN $=5 \mathrm{mM}$; $[\mathrm{Ir}]=1 \mu \mathrm{M}$; $\mathrm{pH} 1$ by $\mathrm{HNO}_{3}$ ). The inset shows identical behavior for both catalysts initially, and remarkably higher activity for complex $\mathbf{2}$ compared to 1 after the bifurcation time $t_{B}$ (note the absence of any significant induction time).

The time of bifurcation $t_{B}$ was extracted from the interception of the slopes of the initial rate (at early $t$ ) and the linear 
high rate for $\mathbf{2}$ as illustrated in the inset of Figure 2. Interestingly, $t_{B}$ depends on the concentration of the catalyst but is independent of the CAN concentration, which is used in large excess (Figure 3). The furcation occurs later when [Ir] is low, suggesting that the initially formed active species $\left(\mathrm{Ir}_{\mathrm{A}}\right)$ - presumably similar for $\mathbf{1}$ and $\mathbf{2}$ - undergoes an associative transformation that is induced by the octyl groups, leading to a much more complex and active species $\left(\operatorname{Ir}_{B}\right)$ when $\mathrm{CAN}$ is used as sacrificial oxidant. Irrespective of the chemical nature of $\operatorname{Ir}_{B}$, the combination of $\mathbf{2}$ and $\mathrm{CAN}$ results in 10 times higher TOFs than with 1 and CAN. For complex 2 , the activity depends on the concentration of both catalyst and CAN (Figure 4). For example, at $5 \mathrm{mM}$ CAN concentration, a maximum TOF $=112 \mathrm{~min}^{-1}$ was observed at $[\mathrm{Ir}]=0.7$ $\mu \mathrm{M}$, while at $10 \mathrm{mM}$ CAN, the highest $\mathrm{TOF}=74 \mathrm{~min}^{-1}$ was achieved at $[\mathrm{Ir}]=3.5 \mu \mathrm{M}$. The dependence of the oxygen evolution rate on the iridium concentration is qualitatively similar at different CAN concentrations and reveals an optimum rather than a maximum in iridium concentration. This behavior might point to a steady state concentration of active species which has a maximum that is determined by both [Ir] and [CAN].

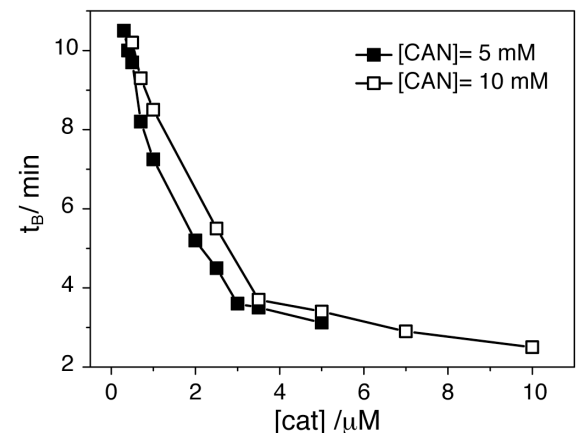

Figure 3. Dependence of bifurcation time $t_{B}$ on concentration of 2 for two values of CAN concentration (determined by UV-Vis spectroscopy).

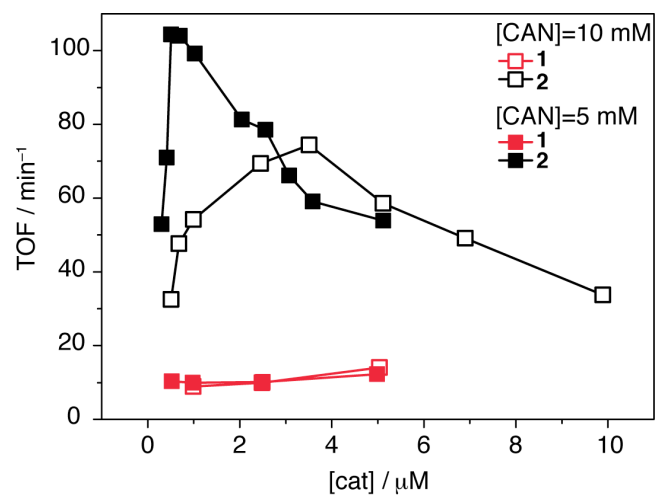

Figure 4. Different behavior of complexes 1 and 2: while the activity of complex 1 is independent of catalyst concentration and activity, complex 2 reveals rate variability determined by the concentration of iridium and CAN (determined by UV-Vis spectroscopy).
The markedly higher activity of complex 2 with CAN appears to be related to an associative process, as indicated by the dependence of $t_{B}$ on the iridium concentration (Figure 3). A plausible hypothesis for association involves the formation of micelles due to the amphiphilic character of complex 2 with long aliphatic substituents. Such micelles may organize the active iridium centers in close mutual proximity and may thus facilitate the usually rate-limiting $\mathrm{O}-\mathrm{O}$ bond formation step through an I2M-type mechanism. ${ }^{18 a-b}$

In order to probe a potential associative process and the self-aggregation tendency of $\mathbf{1}$ and $\mathbf{2}$, diffusion NMR experiments were performed. These measurements allow the selfdiffusion translational coefficient $\left(D_{t}\right)$ of a species in solution to be determined..$^{19}$ Because $\mathrm{D}_{\mathrm{t}}$ is related to the hydrodynamic radius, the dimension of molecular and supramolecular species can be accurately deduced. The average level of aggregation is readily disclosed by the aggregation number $(\mathrm{N})$, defined as the ratio between the measured hydrodynamic volume $\left(\mathrm{V}_{\mathrm{H}}\right)$ and that expected for the monomeric starting species $\left(\mathrm{V}_{\mathrm{H}}{ }^{0}\right){ }^{20}$ Despite the presence of an octyl chain, $\mathbf{2}$ exhibits only a marginally higher self-aggregation tendency than 1 (Table 2). In $\mathrm{D}_{2} \mathrm{O}$, aggregation numbers were $\mathrm{N}=1.4$ and 1.8 for $1(0.3 \mathrm{mM})$ and $2(0.1 \mathrm{mM})$, respectively, suggesting for both compounds an equilibrium between a monomeric and dimeric species that is slightly more shifted towards the dimer for $\mathbf{2}$, due presumably to enhanced hydrophobic interactions. In order to explore the self-aggregation tendency of $\mathbf{1}$ and $\mathbf{2}$ under conditions that are as relevant as possible to catalysis, titration experiments were performed with CAN $\left(1 \mathrm{M} \mathrm{DNO}_{3}, \mathrm{pD}=1\right)$ and $\mathrm{NaIO}_{4}$. A gradual oxidative transformation of the $\mathrm{Cp}^{*}$ ligand was detected, initiated by $\mathrm{Cp}^{*}-\mathrm{CH}_{3}$ to $\mathrm{Cp}^{*}-\mathrm{CH}_{2} \mathrm{OH}$ oxidation, ${ }^{9}$ and ultimately leading to the complete disappearance of the $\mathrm{Cp}^{*}$ resonance from the ${ }^{1} \mathrm{H}$ NMR spectrum. ${ }^{10 a}$ The oxidative transformation of $\mathrm{Cp}^{*}$ is essentially identical with $\mathrm{CAN}$ and $\mathrm{NaIO}_{4}$, though the process is much faster with CAN. ${ }^{21}{ }^{1} \mathrm{H}$ diffusion NMR experiments with acquisition time up to 3 days were performed using 0.1-1.0 mM solutions of 1 and 2 in the presence of 20-30 equivalents of oxidant. ${ }^{17}$ Under these conditions, the phenyl and alkyl protons appeared as broad resonances, yet sufficiently intense for evaluating $D_{t}$. The deduced $\mathrm{V}_{\mathrm{H}}$ values for $\mathbf{1}$ and $\mathbf{2}$ changed only little (Table 2) and gave aggregation numbers $\mathrm{N}=1.4$ and 1.7 (for 1 with $\mathrm{CAN}$ and $\mathrm{NaIO}_{4}$, respectively) and $\mathrm{N}=2.0$ (for 2 with either CAN or $\mathrm{NaIO}_{4}$ ), when referenced to $\mathrm{V}_{\mathrm{H}}{ }^{0}$ of the initial precursors. Larger aggregation numbers result when assuming that the $\mathrm{Cp}^{*}$ ligand completely transforms into acetic ac$\mathrm{id}$, formic acid and $\mathrm{CO}_{2}$ and that a dimeric iridium species $\left[(\mathrm{C}, \mathrm{N}) \mathrm{X}_{2} \operatorname{Ir}\left(\mu^{2}-\mathrm{X}\right)_{2} \operatorname{Ir} \mathrm{X}_{2}(\mathrm{C}, \mathrm{N})\right]$ forms, analogous to Crabtree's proposal $(\mathrm{X}=$ oxo, hydroxo $) .{ }^{22}$ The hydrodynamic volumes for these dimers derived from $\mathbf{1}$ and $\mathbf{2}$ were estimated to be $657 \AA^{3}$ and $951 \AA^{3}$, respectively. These values agree very well with the measured $V_{H}$ for the active species evolving from 1, while the species originating from 2 unveils a 
slightly higher aggregation tendency. Irrespective of the exact nature, the self-association propensity of $\mathbf{2}$ is not significantly different with either $\mathrm{CAN}$ or $\mathrm{NaIO}_{4}$, thus suggesting that the $\mathrm{SO}$ is not directly involved in the associative process. Further support for the formation of small aggregates only was obtained from DLS experiments, which did not reveal any particles in the 3-500 $\mathrm{nm}$ hydrodynamic radius range.

Table 2. Oxidant-dependent hydrodynamic volume $\left(\mathrm{V}_{\mathrm{H}}\right)$ and aggregation number $(\mathrm{N})$ of complexes 1 and 2 from diffusion NMR spectroscopy. ${ }^{2}$

\begin{tabular}{cccc}
\hline complex & oxidant & $\mathrm{V}_{\mathrm{H}} / \AA^{3}$ & $\mathrm{~N}$ \\
\hline 1 & none & 670 & 1.4 \\
1 & $\mathrm{NaIO}_{4}$ & 790 & 1.7 \\
1 & $\mathrm{CAN}$ & 690 & 1.4 \\
2 & none & 1080 & 1.8 \\
2 & $\mathrm{NaIO}_{4}$ & 1180 & 2.0 \\
2 & $\mathrm{CAN}$ & 1214 & 2.0 \\
\hline
\end{tabular}

a Aggregation number $\mathrm{N}$ based on $\mathrm{V}_{\mathrm{H}}{ }^{0}(\mathbf{1})=470 \AA^{3}$ and $\mathrm{V}_{\mathrm{H}}{ }^{0}(2)=600 \AA^{3 ;}$ see reference 19.

The general picture emerging from our results is consistent with the generation of several catalytically active species for both $\mathbf{1}$ and 2, all having molecular nature, due to the oxidative transformation of $\mathrm{Cp}^{*}$ with both $\mathrm{CAN}$ and $\mathrm{NaIO}_{4}$. According to diffusion NMR measurements, it is reasonable to conclude that all species stemming from $\mathbf{2}$ have a slightly higher tendency to self-aggregate than analogues derived from 1 . The self-aggregation of one specific species derived from the oxidative transformation of $\mathbf{2}$ conceivably generates a catalyst with an extraordinarily high activity. Among the various potential reasons for the particular role of CAN, we speculate that oxidative transformation with $\mathrm{NaIO}_{4}$ is unfavorably slow compared with catalytic turnover frequencies, while $\mathrm{Cp}^{*}$ oxidation with $\mathrm{CAN}$ occurs readily to form the highly active aggregate. In such a model, the steady state concentration of the self-assembled species is finely tuned by CAN and catalyst concentrations thus rationalizing the delicate balance required for optimum rates ( $c f$ Figure 4).

In conclusion, a simple and remote modification in the ancillary carbene ligand of triazolylidene $\operatorname{Ir}\left(\mathrm{Cp}^{*}\right)$ complexes leads to an increase of water oxidation by one full order of magnitude and affords one of the highest oxygen evolution rates that has been recorded thus far for iridium-catalyzed water oxidation. The substantial rate enhancement is potentially induced by a specific aggregation process. Even though the incorporation of lipophilic elements into a catalyst for water oxidation appears highly counterintuitive, the introduction of long alkyl chains may become an essential feature when designing molecular water oxidation catalysts with exceptionally high activity, also when considering metal complexes other than those based on iridium.

\section{ASSOCIATED CONTENT}

Supporting Information. Synthetic procedures, chemical water oxidation details, NMR measurements, crystallographic details and DLS measurements. This material is available free of charge via the Internet at http://pubs.acs.org.

\section{AUTHOR INFORMATION}

\section{Corresponding Author}

alceo.macchioni@unipg.it

martin.albrecht@ucd.ie

\section{Notes}

The authors declare no competing financial interest.

\section{ACKNOWLEDGMENT}

This work was financially supported by SABIC, the European Research Council (CoG 615653), Science Foundation Ireland, and COST Action CM1205 (CARISMA).

\section{REFERENCES}

1) (a) Alstrum-Acevedo, J. H.; Brennaman, M. K.; Meyer, T. J. Inorg. Chem. 2005, 44, 6802-6827. (b) Lewis, N. S.; Nocera, D. G. Proc. Natl. Accad. Sci. 2006, 103, 15729-15735. (c) Balzani, V.; Credi, A.; Venturi, M. ChemSusChem 2008, 1, 26-58. (d) Gust, D.; Moore, T. A.; Moore, A. L. Acc. Chem. Res. 2009, 42, 1890-1898. (e) McDaniel, N. D.; Bernhard, S. Dalton Trans. 2010, 39, 10021-10030. (f) Berardi, S.; Drouet, S.; Francàs, L.; Gimbert-Suriñach, C.; Guttentag, M.; Richmond, C.; Stoll, T.; Llobet, A. Chem. Soc. Rev. 2014, 43, 7501-7519.

2) For leading and recent references, see: (a) Dau, H.; Limberg, C.; Reier, T.; Risch, M.; Roggan, S.; Strasser, P. Chem CatChem 2010, 2, 724-761. (b) Cao, R.; Lai, W. ; Du, P. Energy Environ. Sci. 2012, 5, 8134-8157. (c) Liu, X.; Wang, F. Coord. Chem. Rev. 2012, 256, 1115-1136. (d) Hetterscheid, D. G. H.; Reek, J. N. H. Angew. Chem. Int. Ed. 2012, 51, 9740 9747. (e) Wasylenko, D. J.; Palmer, R. D.; Berlinguette, C. P. Chem. Commun. 2013, 49, 218-227. (f) Kärkäs, M. D.; Verho, O.; Johnston, E. V.; Åkermark, B. Chem. Rev. 2014, 114, 11863-12001.

3) For a recent example of a molecular catalyst immobilized onto a functional material see: Savini, A.; Bucci, A.; Nocchetti, M.; Vivani, R.; Idriss, H.; Macchioni, A. ACS Catal. 2015, 5, 264-271.

4) Molecular Water Oxidation, Llobet, A. , Ed., Wiley-Interscience: New York, 2014.

5) Duan, L.; Bozoglian, F.; Mandal, S.; Stewart, B.; Privalov, T.; Llobet, A.; Sun, L. Nat. Chem. 2012, 4, 418-423.

6) Woods, J. A.; Bernhard, S.; Albrecht M. in: Molecular Water Oxidation, Llobet, A., Ed., Wiley-Interscience: New York, 2014; pp 113-133.

7) McDaniel, N. D.; Coughlin, F. J.; Tinker, L. L.; Bernhard, S. J. Am. Chem. Soc. 2008, 130, 210-217.

8) For selected examples, see: (a) Hull, J. F.; Balcells, D.; Blakemore, J. D. C.; Incarvito, D.; Eisenstein, O.; Brudvig, G. W.; Crabtree, R. H. J. Am. Chem. Soc. 2009, 131, 8730-8731. (b) Savini, A.; Bellachioma, G.; Ciancaleoni, G.; Zuccaccia, C.; Zuccaccia, D.; Macchioni, A. Chem. Commun. 2010, 46, 9218-9219. (c) Hetterscheid, D. G. H.; Reek, J. N. H. Chem. Commun. 2011, 47, 2712-2714. (d) Marquet, N.; Gärtner, F.; Losse, S.; Pohl, M.-M.; Junge, H.; Beller, M. ChemSusChem 2011, 4, 1598-1600. (e) Bucci, A.; Savini, A.; Rocchigiani, L.; Zuccaccia, C.; Rizzato, S.; Albinati, A.; Llobet, A.; Macchioni, A. Organometallics 2012, 31, 8071-8074. (f) Wang, C.; Wang, J.-L.; Lin, W. J. Am. Chem. Soc. 2012, 134, 19895-19908. (g) Codolà, Z.; Cardoso, J. M. S.; Royo, B.; Costas, M.; Fillol, J. L. Chem. Eur. J. 2013, 19, 7203-7213. (h) DePasquale, J.; Nieto, I.; Reuther, L.E.; Herbst-Gervasoni, C. J.; Paul, J. J.; Mochalin, V.; Zeller, M.; Thomas, C. 
M.; Addison, A. W.; Papish, E. T. Inorg. Chem. 2013, 52, 9175-9183. (i) Lewandowska-Andralojc, A.; Polyansky, D. E.; Wang, C.-H., Wang, W.-H.; Y. Himeda, Fujita, E. Phys. Chem. Chem. Phys 2014, 16, 11976-11987. (j) Savini, A.; Bucci, A.; Bellachioma, A.; Giancola, S.; Palomba, F.; Rocchigiani, L.; Rossi, A.; Suriani, A.; Zuccaccia, C.; Macchioni A. J. Organomet. Chem. 2014, 771, 24-32.

9) (a) Grotjahn, D. B.; Brown, D. B.; Martin, J. K.; Marelius, D. C.; Abadjian, M.-C.; Tran, H. N.; Kalyuzhny, G.; Vecchio, K. S.; Specht, Z. G.; Cortes-Llamas, S. A.; Miranda-Soto, V.; van Niekerk, C.; Moore, C. E.; Rheingold, A. L. J. Am. Chem. Soc. 2011, 133, 19024-19027. (b) Savini, A.; Belanzoni, P.; Bellachioma, G.; Zuccaccia, C.; Zuccaccia, D; Macchioni, A. Green Chem. 2011, 13, 3360-3374. (c) Zuccaccia, C.; Bellachioma, G.; Bolaño, S.; Rocchigiani, L.; Savini, A.; Macchioni, A. Eur. J. Inorg. Chem. 2012, 1462-1468.

10) (a) Zuccaccia, C.; Bellachioma, G.; Bortolini, O.; Bucci, A.; Savini, A.; Macchioni, A. Chem. Eur. J. 2014, 20, 3446-3456. (b) Savini, A.; Bucci, A.; Bellachioma, G.; Rocchigiani, L.; Zuccaccia, C.; Llobet, A.; Macchioni, A. Eur. J. Inorg. Chem. 2014, 690-697.

11) (a) Joya, K.S.; Subbaiyan, N. K.; D’Souza, F.; de Groot, H. J. M. Angew. Chem. Int. Ed. 2012, 51, 9601-9605. (b) Diaz-Morales, O.; Hersbach, T. J. P.; Hetterscheid, D. G. H.; Reek, J. N. H.; Koper, M. T. M. J. Am. Chem. Soc. 2014, 136, 10432-10439.

12) (a) Thomsen, J. M.; Sheehan, S. W.; Hashmi, S. M.; Campos, J.; Hintermair, U.; Crabtree, R. H.; Brudvig, G. W. J. Am. Chem. Soc. 2014, 136, 13826-13834. (b) Savini, A.; Bellachioma, G.; Bolaño, S.; Rocchigiani, L.; Zuccaccia, C.; Zuccaccia, D.; Macchioni, A. ChemSusChem 2012, 5, 1415-1419.

13) (a) Lalrempuia, R.; McDaniel, N. D.; Müller-Bunz, H.; Bernhard, S. Albrecht, M. Angew. Chem. Int. Ed. 2010, 49, 9765-9768. (b) Petronilho, A. Rahman, M.; Woods, J. A.; Al-Sayyed, H.; Müller-Bunz, H.; Don, M. J. M.; Bernhard, S.; Albrecht, M. Dalton Trans. 2012, 41, 13074-13080. (c) Woods, J. A. Lalrempuia, R.; Petronilho, A.; McDaniel, N. D.; Müller-Bunz, H.; Albrecht, M.; Bernhard, S. Energy Env. Sci. 2014, 7, 2316-2328.
14) (a) Mathew, P.; Neels, A.; Albrecht, M. J. Am. Chem. Soc. 2008, 130, 13534-13535. (b) Guisado-Barrios, G.; Bouffard, J.; Donnadieu, B.; Bertrand, G. Angew. Chem. Int. Ed. 2010, 49, 4759-4762. (c) Crowley, J. D.; Lee, A.-L.; Kilpin, K. J. Aust. J. Chem. 2011, 64, 1118-1132. (d) Donnelly, K. F.; Petronilho, A.; Albrecht, M. Chem. Commun. 2013, 49, 1145 1159.

15) For a review on the properties of sacrificial oxidants for WO see: (a) Parent, A. R.; Crabtree, R. H.; Brudvig, G. W. Chem. Soc. Rev. 2013, 42, 2247-2252. For a more recent paper on $\mathrm{IO}_{4}{ }^{-}$as oxidant for WO see: (b) Hetterscheid, D. G. H.; Reek, J. N. H. Eur. J. Inorg. Chem. 2014, 742-749.

16) Kwok, S. W.; Fotsing, J. R.; Fraser, R. J.; Rodionov, V. O.; Fokin, V. V. Org. Lett. 2010, 12, 4217-4219.

17) See supporting information for details.

18) (a) Romain, S.; Vigara, L.; Llobet, A. Acc. Chem. Res. 2009, 42, 1944-1953. (b) Petronilho, A.; Woods, J. A.; Bernhard, S.; Albrecht, M. Eur. J. Inorg. Chem. 2014, 708-714.

19) Macchioni, A.; Ciancaleoni, G.; Zuccaccia, C.; Zuccaccia, D. Chem Soc. Rev. 2008, 37, 479-489.

20) $\mathrm{V}_{\mathrm{H}}{ }^{0}$ was derived by multiplying the van der Waals volume of the crystal structures of 1 and 2 by 1.3 , see reference 19 for details.

21) No degradation of the triazolylidene ligand was noted under these conditions. Exposure of complex 2 to 40 equivalent of CAN in $1 \mathrm{M} \mathrm{HNO}_{3}$ for $2 \mathrm{~h}$, and subsequent extraction of organic residues with $\mathrm{CH}_{2} \mathrm{Cl}_{2}$ did not reveal any formation of octanol, octanal, or octanoic acid in the organic layer, even though such compounds would readily extract from acidic water into $\mathrm{CH}_{2} \mathrm{Cl}_{2}$. Instead, only small traces of complex 2 were recovered. These experiments are in agreement with a robust ligand structure under these oxidizing and acidic conditions, and do not support oxidative $\mathrm{C}-\mathrm{N}$ bond cleavage in the triazolylidene ligand.

22) Hintermair, U.; Sheehan, S. W.; Parent, A. R.; Ess, D. H.; Richens, D. T.; Vaccaro, P.H.; Brudvig, G. W.; Crabtree, R. H. J. Am. Chem. Soc. 2013, 135, 10837-10851.

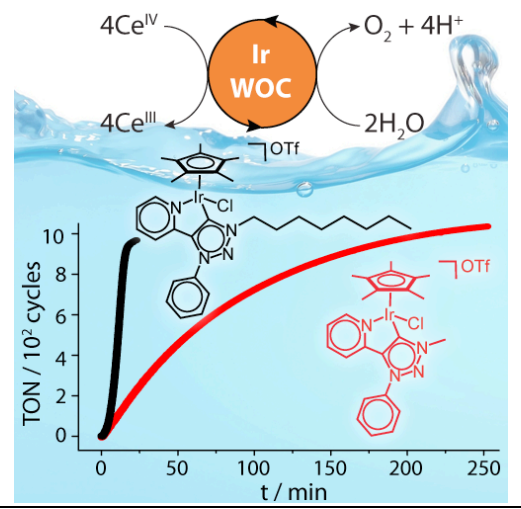

